DOI: $10.5965 / 25946412222018104$

\title{
MATEMÁTICA E ARTES: CONTEXTO DE APRENDIZAGENS SIGNIFICATIVAS
}

\author{
Jefferson Correia da Conceição \\ Doutor em Ciências da Educação - UNEB/F.SS.S \\ jeffersoncorreia2@gmail.com
}

\begin{abstract}
Resumo
A aprendizagem matemática, por vezes, é muito confundida com medo, dificuldade, sem atrativos, sem cor e sem vida. Todavia, pode-se constatar mediante algumas ações pedagógicas realizadas por meio de oficinas de expressão plástica, que ocorrem no Projeto de Extensão em andamento, justamente o contrário: beleza, cor, movimento, criatividade, arte e muito envolvimento, pois o público envolvido - licenciandos em Matemática e pessoas da Terceira Idade, regularmente matriculados na Universidade Aberta a Terceira Idade, participam de forma ativa na elaboração do próprio conhecimento. É possível, de forma lúdica e por meio de algumas expressões artísticas painéis, esculturas, jogos etc., discutir e exemplificar alguns conceitos matemáticos presentes na geometria, tais como: ponto, simetria, formas regulares e irregulares, dentre outras, por intermédio de uma prática pedagógica amparada pela ludicidade e pelas artes, uma vez que, as atividades se tornam interessantes e prazerosas. Dessa forma, este relato de experiência busca evidenciar alguns resultados e reflexões, fruto do trabalho pedagógico que ocorre com o envolvimento da Matemática com as Artes, ao ressaltar os benefícios tangíveis - aprendizagens, motivação, alegria, disposição, reminiscências, que são declarados pelos envolvidos, por intermédio das ações citadas.
\end{abstract}

Palavras-chave: Aprendizagem. Matemática. Artes. Geometria. Ludicidade.

\section{MATHEMATICS AND ARTS: CONTEXT OF SIGNIFICANT LEARNING}

\begin{abstract}
Mathematical learning is sometimes confused with fear, difficulty, unattractive, colorless, and lifeless. However, it can be seen through some pedagogical actions carried out through workshops of plastic expression, which occur in the Extension Project in progress, just the opposite: beauty, color, movement, creativity, art and a lot of involvement, since the public involved - graduates in Mathematics and people of the Third Age, regularly enrolled in Open University at the Third Age, participate actively in the elaboration of their own knowledge. It is possible, in a playful way and through some artistic expressions - panels, sculptures, games etc, to discuss and exemplify some mathematical concepts present in geometry, such as: point, symmetry, regular and irregular shapes, among others, through a pedagogical practice supported by playfulness and the arts, once the activities become interesting and enjoyable. Thus, this experience report seeks to highlight some results and reflections, the result of the pedagogical work that occurs with the involvement of Mathematics with the Arts, highlighting the tangible benefits - learning, motivation, joy, disposition, reminiscences that are stated by those involved, through the aforementioned actions.
\end{abstract}

Key-words: Learning. Mathematics. Art. Geometry. Ludicidade. 


\section{MATEMÁTICA Y ARTES: \\ CONTEXTO DE APRENDIZAJE SIGNIFICADO}

\section{Resumen}

El aprendizaje matemático, a veces, es muy confundido con miedo, dificultad, sin atractivo, sin color y sin vida. Sin embargo, se puede constatar mediante algunas acciones pedagógicas realizadas por medio de talleres de expresión plástica, que ocurren en el Proyecto de Extensión en marcha, justamente lo contrario: belleza, color, movimiento, creatividad, arte y muy implicación, pues el público involucrado - los licenciados en Matemáticas y personas de la Tercera Edad, regularmente matriculados en la Universidad Abierta la Tercera Edad, participan de forma activa en la elaboración del propio conocimiento. Es posible, de forma lúdica y por medio de algunas expresiones artísticas paneles, esculturas, juegos, etc, discutir y ejemplificar algunos conceptos matemáticos presentes en la geometría, tales como: punto, simetría, formas regulares e irregulares, entre otras, por intermedio práctica pedagógica amparada por la ludicidad y las artes, una vez que las actividades se vuelven interesantes y placenteras. De esta forma, este relato de experiencia busca evidenciar algunos resultados y reflexiones, fruto del trabajo pedagógico que ocurre con el envolvimiento de la Matemática con las Artes, al resaltar los beneficios tangibles - aprendizajes, motivación, alegría, disposición, reminiscencias, que son declarados por los involucrados, por intermedio de las acciones citadas.

Palabras clave: Aprendizaje. Matemáticas. Artes. Geometría. Lúdico. 


\section{INTRODUÇÃO}

A união do raciocínio lógico com a criatividade sempre foi responsável por grandes avanços do homem. Da lâmpada elétrica aos atuais smartphones, passando pelo avião e pelo relógio de pulso, significativas inovações são e foram alcançadas com base nessa combinação. No entanto, desenvolver essas diferentes formas de funcionamento da mente representa um desafio para os educadores, sobretudo quando se tenta articular componentes curriculares aparentemente tão distintos como Matemática e Artes.

Curiosamente, os estudantes são naturalmente criativos e inovadores, características que se enfraquecem à medida que "aprendem" com os adultos a forma "correta" de agir e pensar. Quando, por exemplo, um estudante realiza uma pintura de um sol azul com um céu vermelho, logo aparece um adulto para "ensinar" que as cores estão erradas. O que leva a essa recomendação? Existe prejuízo em deixar um estudante pintar dessa forma? De maneira geral, ser criativo tem mais a ver com "desaprender" antigas formas de pensar do que com adquirir habilidades especiais.

É necessário que os estudantes consigam responder "para que" estão aprendendo tal conteúdo, assim como, os docentes mediadores possam responder "para que" estão mediando,

a fim de que estabeleçam vínculos entre escola e vida e, além disso, vejam relações entre conteúdos dos diversos componentes curriculares, uma vez que, como se sabe, o conhecimento matemático não é estanque e, com isso, aprendam, percebendo, então, que a

escola tem sentido. É preciso saber com clareza, quais as contribuições de cada um dos conteúdos matemáticos para os processos de desenvolvimento e aprendizagem dos estudantes. Por muito tempo, os estudantes foram concebidos como seres passivos e que apenas deveriam ouvir e reproduzir o que ouviam, quando solicitados. Esse perfil de ser humano cabe nos dias atuais? Faz sentido um "alguém" que não interaja com a vida cotidiana, seja em que instância

for? Então, como manter "aquele jeito" de “ensinar” matemática, se não reflete, não interage, não dialoga ou não articula cada vez mais com os dias atuais?

Dessa forma, as atividades realizadas na Universidade Aberta a Terceira Idade UATI, por meio das oficinas de expressão plástica, tem como objetivo articular conceitos matemático - geométricos, tais como: ponto, linha, superfície, ângulos, formas regulares e irregulares, simetria e assimetria, dentre outros, mediante atividades artísticas - painéis, quadros, esculturas etc., desde que, evidenciem os conceitos citados, dentre outros. 


\section{DESENVOLVIMENTO}

Considerando-se os questionamentos e percepções anteriores, é que se pensa na possibilidade de articulação das expressões e linguagens artísticas - música, teatro ou expressão cênica, dança ou expressão corporal, expressão literária, expressão oral e as artes plásticas ou visuais, com todos os seus desdobramentos expressivos, como aliadas pedagógicas numa prática que se quer dinâmica, viva, lúdica e motivadora de aprendizagens matemáticas.

A Matemática e a Arte são consideradas linguagens universais, promovendo uma visão de mundo. Gusmão (2013, p. 79), coloca o seguinte:

[...] a educação matemática pela arte precisa incorporar mecanismos para desrobotizar, libertar a matemática. E esses mecanismos... podem ser encontrados nas capacidades provenientes da arte. A Matemática como a Arte é uma atividade primária da vida humana e está em todo lugar.

Ressalta-se, que tudo isso deve estar integrado aos aspectos lúdicos ${ }^{1}$ e prazerosos que devem se apresentar durante as práticas pedagógicas, sobretudo no que diz respeito ao conhecimento matemático - geométrico, por meio da Arte.

Em outras palavras, as possibilidades expressivas das Artes, quando adotada de forma articulada na prática pedagógica objetivando a aprendizagem matemática dos estudantes poderá trazer mais conhecimentos e ser mais eficaz como portadora de informação e sentido. Isto porque a aprendizagem matemática deve ser também um convite ao exercício prático de aprender a ver, observar, ouvir, tocar, atuar e refletir sobre elas. Assim, os indivíduos poderão perceber melhor as informações que lhes são apresentadas. No que diz respeito às teorias enquanto alimento para prática pedagógica, vejamos o que é dito por D’Ambrósio (2006, p. 79).

[...] Entre teoria e prática persiste uma relação dialética que leva o indivíduo a partir para a prática equipado da teoria e a praticar de acordo com essa teoria até atingir os resultados desejados. Toda teorização se dá em condições ideais e somente na prática serão notados e colocados em evidencia certos pressupostos que não podem ser identificados apenas teoricamente. Isto é, partir para a prática é um mergulho no desconhecido.

${ }^{\mathrm{T}}$ Relativo a jogos, brinquedos e divertimentos.

Cidadania em Ação: Revista de Extensão e Cultura, Florianópolis (SC), v. 2, n.2, juL./dez. 2018. 
Assim, essas ações com perfis integradores, conseguem contemplar os objetivos interacionistas entre Matemática/Geometria e Artes, quando se expressam e se visualizam conceitos matemáticos - geométricos por meio das Artes Visuais, uma vez que, devem ser compreendidos também, em função da curiosidade, interesse e envolvimento que são manifestados pelos estudantes no decorrer das ações empreendidas, além, evidentemente, dos resultados práticos evidenciados. Isso nos permite propiciar a tomada de consciência da existência de uma produção genuína, real e concreta, em permanente elaboração acerca do conhecimento matemático - geométrico articulado com as Artes.

\section{PERCURSOS E EVIDÊNCIAS DE APRENDIZAGENS}

Para efetivação das experiências ora relatadas, organiza-se a apresentação inicial das ações com os estudantes, por meio de esclarecimentos sobre os objetivos e propósitos do encontro. Os participantes são pessoas da Terceira Idade, regularmente matriculadas na UATI, numa faixa etária a partir dos 60 anos, conforme orientações da Universidade.

São orientados pelo docente coordenador do projeto e pelo licenciando em Matemática - monitor bolsista selecionado, para perceberem as imagens, o corpo e formas visuais em geral de modo livre, para que possam desenvolver cada vez mais a observação, a atenção e o conhecimento matemático que já possuem para agregar aos propósitos do trabalho sugerido.

Solicita-se que observem também, o espaço da sala de aula e, estabeleçam um tempo determinado, dando-se a seguir um sinal para que possam começar alguns comentários acerca de algumas imagens ou objetos presentes no ambiente, quando cada estudante poderá acrescentar algum comentário sobre o que observou em termos de formas visuais e as informações matemáticas implícitas no ambiente e/ou no objeto analisado.

As atividades ocorrem semanalmente durante os semestres acadêmicos, por meio de uma carga horária de 03 (três) aulas, mediante oficinas de expressão plástica, numa sala específica da Universidade. 
Figuras 01 e 02 - Registros algumas ações do Projeto de Extensão
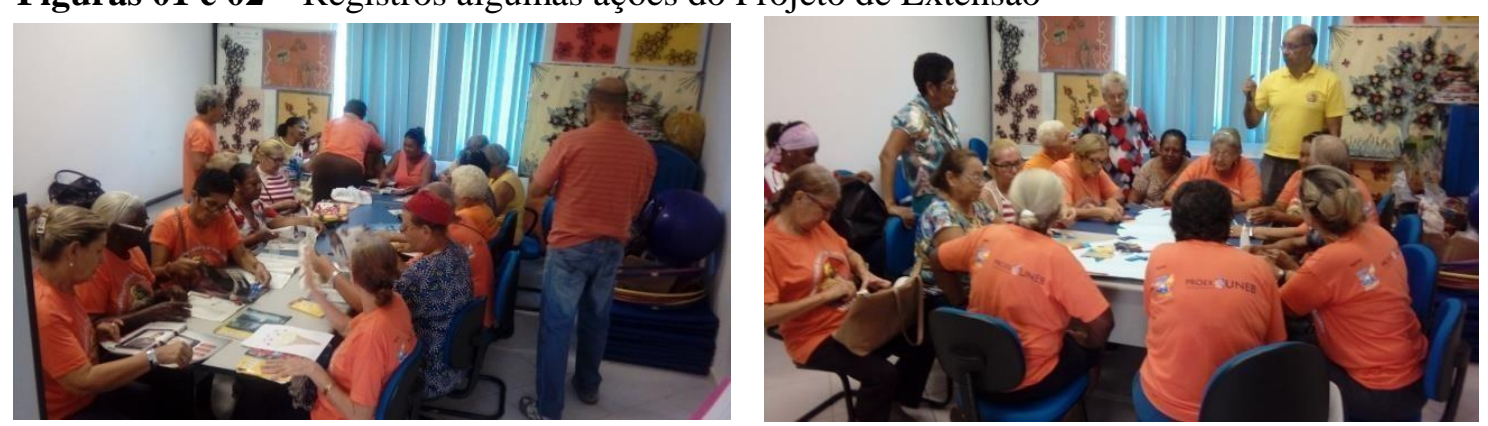

Fonte: Acervo do autor (2017)

Os participantes se empenham nas atividades propostas, na formulação de alguns comentários e, volta-se a interferir nos diálogos para solicitar que olhem mais uma vez para o espaço da sala de aula, para que possam ampliar os comentários do grupo com relação à dinâmica das atividades em curso, no que tange ao conhecimento matemático - geométrico. Nesse momento, realizam-se algumas dinâmicas como sensibilização, que articulam a matemática com a música, com a dança, com o teatro, com a literatura, com a oralidade e com as artes visuais, mediante alguns jogos e ações lúdicas variadas, para favorecer a percepção de algumas possibilidades articuladoras entre as citadas áreas de conhecimentos.

No decorrer das atividades, realizam-se comentários acerca de alguns conceitos e conteúdos matemáticos - linhas, planos, ângulos, formas regulares e irregulares, simetrias e assimetrias, dentre outros que se fizeram presentes nos exercícios realizados, com o propósito de esclarecer que tais aspectos que permeiam o trabalho serão utilizados como parte das criações e que as atividades deverão servir para descobrir referências matemáticas no ambiente, no cotidiano, na vida em geral. Esclarecendo melhor a questão, Contador (2011, p. 172) diz o seguinte sobre essa questão:

A Matemática está presente numa obra de arte através da estética e do equilíbrio, é por intermédio dela que conseguimos testemunhar esse grande encontro: Arte e Matemática e, quando ambas passam a fazer parte do ideal do artista, o mundo com sua visão particular, podem ser retratados de forma real, a outros e a si próprio.

Depois de realizados alguns esclarecimentos e comentários, estimula-se os estudantes para que, a partir das informações, materiais disponíveis e solicitados e, mediante a imaginação criadora, elaborem atividades em sintonia com uma das linguagens ou expressões artísticas tais como: música, teatro, expressão corporal, literatura, oralidade ou artes visuais, conforme solicitado em cada encontro, de modo que, apareçam nas atividades realizadas pelos estudantes algumas representações de conteúdos, conceitos e elementos discutidos no 
encontro no que diz respeito ao conhecimento matemático.

Ampliam-se as discussões nos encontros seguintes, sempre perguntando algo comentado nos encontros anteriores, para percebermos assimilações, lembranças, interrelações dos conteúdos - linhas, planos, ângulos, formas regulares e irregulares, simetrias e assimetrias, dentre outros assuntos discutidos anteriormente, por estarem presentes na Matemática e nas Artes em geral, sempre com o propósito de estabelecermos conexões com as propostas do dia, uma vez que, consideramos tais dados como depoimentos qualitativos que poderão favorecer planejamentos e projetos vindouros, assim como, importantes para as atividades propostas no momento.

\section{EDUCAÇÃO MATEMÁTICA E ARTES}

Sabe-se que, a Educação Matemática foi concebida mediante ações reflexivas, almejando-se um ensino que possibilitasse aos estudantes proceder a análises, discussões, conjecturas, apropriação de conceitos e conteúdos, formulação de ideias, ou seja, de amplitudes conceituais significativas. A Matemática se torna uma ligação entre campo de conhecimento e disciplina escolar segundo Helbel (2013). Para Cifuentes (2005, p. 59) a compreensão é a seguinte:

\footnotetext{
A Matemática não deveria ser estudada priorizando-se apenas seus conteúdos, senão interpretada também em seus contextos históricos e culturais, e pondo em evidência não somente sua utilidade senão também a sua beleza.
}

Perante a Diretriz Curricular de Matemática, da Secretaria de Estado da Educação - PR (SEED, 2008) para a Educação Básica da Rede Pública, os conteúdos de grande amplitude, são entendidos como Conteúdos Estruturantes, organizando-se em:

- Números e Álgebra

- Grandezas e Medidas

- Geometrias

- Funções

- Tratamento da Informação

Com se percebe, mediante os conteúdos estruturantes mencionados e por intermédio de um projeto com tais características integracionistas, pode-se explicitar a articulação das Artes com a Matemática, como criação, como reflexão e transformação do mundo subjetivo e objetivo, como resultado de uma produção conjunta entre a mão, o olho e a consciência individual e coletiva, ainda que, mediante uma forma particular e subjetiva de percepção de 
dados de aprendizagens, que considerem os conteúdos estruturantes conforme as necessidades pedagógicas. A este respeito, vejamos o que é dito por Fainguelernt e Nunes (2006, p. 251).

A matemática e a arte nunca estiveram em campos antagônicos, pois desde sempre caminharam juntas, aliando razão e sensibilidade. Na verdade, podemos observar a influência mútua de uma sobre a outra desde os primeiros registros históricos que temos de ambas. Essas duas áreas sempre estiveram intimamente ligadas, desde as civilizações mais antigas, e são inúmeros os exemplos de sua interação. Muitos povos utilizaram elementos matemáticos na confecção de suas obras: os egípcios com suas monumentais pirâmides e gigantescas estátuas; os gregos com o famoso Parthenon e com seus belíssimos mosaicos; os romanos com suas inúmeras construções com formas circulares, entre elas o Coliseu.

Sabe-se o quanto a Arte e a Matemática influencia no desenvolvimento da intuição e imaginação. Sobre o conhecimento matemático, vale ressaltar o que consta no (PCNEM, 1997, p. 251):

[...] contribui para o desenvolvimento de processos de pensamento e aquisição de atitudes, podendo formar no aluno a capacidade de resolver problemas genuínos, gerando hábitos de investigação, proporcionando confiança e desprendimento para analisar e enfrentar situações novas, propiciando a formação de uma visão ampla e científica da realidade, a percepção da beleza e da harmonia, o desenvolvimento da criatividade e de outras capacidades pessoais.

As atividades artísticas proporcionam a expansão do universo cultural dos estudantes da UATI, abrindo espaço para a participação social, onde aprender Matemática por meio da Arte é uma ideia a ser vislumbrada em sala de aula. Nesta linha de raciocínio, Zaleski Filho (2013, p.25) ressalta:

Pensar a sala de aula como um contexto no qual se desenvolve a atividade matemática requer também pensar em condições para que os alunos sejam levados a formar conjecturas, procurar formas de validá-las, produzir argumentos dedutivos, arriscar respostas para as questões que se formulam, criar formas de representação que contribuam para chegar às soluções que se buscam reformular e reorganizar os velhos conhecimentos à luz dos novos conhecimentos produzidos.

Nessa perspectiva, os estudantes podem se tornar partícipes de descobertas e protagonistas em um processo de investigação, como tem ocorrido nas atividades ora relatadas mediante o projeto de extensão. Desse modo, vale registrar, então, que a perspectiva de Gusmão (2013) sobre Artes e Matemática, coincide com a de Zaleski Filho (2013).

[...] Arte desenvolve a percepção humana, apura o olhar, mostra os objetos cotidianos sob ângulos diferentes, proporcionando a oportunidade de refletir e modificar a maneira de se olhar o mundo. A matemática, olhada e desenvolvida por esse prisma - em conexão com a arte - pode se tornar mais humana, carregada de sensibilidade, de imaginação, de criatividade, de experiência estética e pode permitir ao ser humano uma visão mais totalitária do seu entorno e do mundo. (GUSMÃO, 2013, p. 133) 
Buscam-se aproximar as elaborações dos estudantes da UATI com padrões de realização não habituais, justamente para aguçar o olhar diferenciado e a criatividade com relação ao conhecimento matemático associado às artes.

Figuras 03 e 04 - Registros algumas ações Projeto Extensão
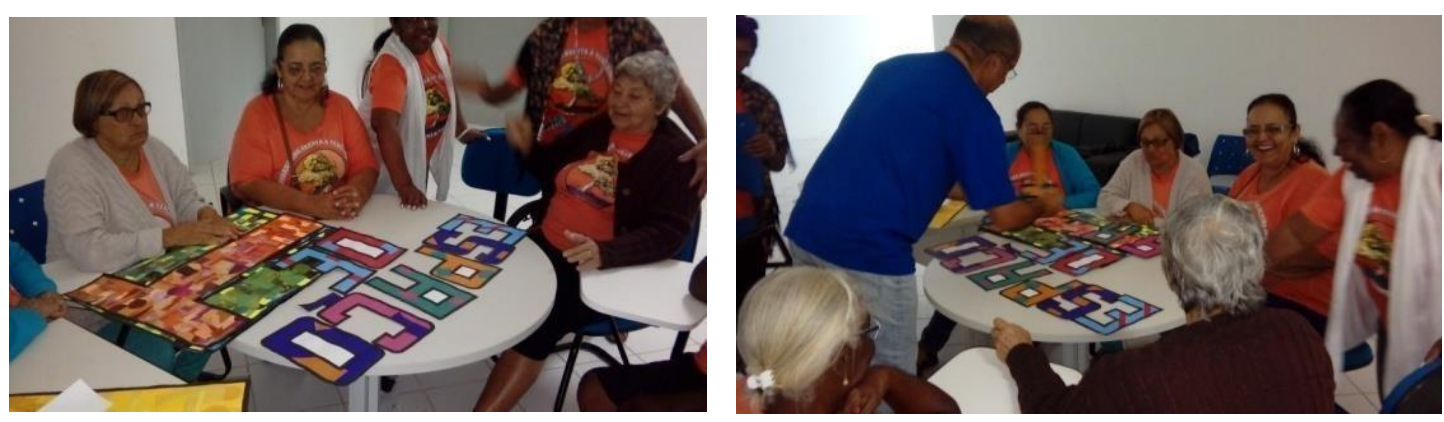

Fonte: Acervo do autor. (2017)

Tal perspectiva poderá ser assegurada ao se trabalhar com informações e estratégias que enfatizem as realizações matemáticas constantes no entorno, a bem da participação dos estudantes na sociedade como cidadãos informados, críticos, integrais e articulados.

Por meio das experiências vivenciadas nas oficinas de expressão plástica, podemos perceber o significado e a importância da aprendizagem matemática - geométrica através das Artes num contexto lúdico e, por conseguinte, da criatividade no cotidiano, o que nos permite perceber dados qualitativos para reflexões e previsões para encontros posteriores. Assim, Mathema (2013, p. 01) diz sobre Matemática e Arte:

Arte e Matemática são áreas distintas e com objetivos de ensino e aprendizagem específicos, ambas caminham em percursos próprios, mas em determinados momentos podem se complementar. Nesse sentido, precisamos ter clareza dos objetivos a serem alcançados nas duas áreas, planejar o trabalho, escolher bons recursos, deixar espaço para escutar dos alunos e elaborar as possíveis situações de problematização.

Ressalta-se que este é um tema de extrema relevância para o processo de ensino/aprendizagem matemática. A respeito da imaginação e criatividade, Bruno Munari (1998, p. 11) se posiciona, argumentando que "Criatividade não significa improvisação sem método: dessa maneira só se cria confusão, e planta-se nos jovens a ilusão de que artistas devem ser livres e independentes".

Projetos de extensão e ensino podem se constituir num importante fator de estímulo para trabalhos que priorizam atividades pedagógicas diversificadas, para públicos distintos ou 
específicos, por intermédio de metodologias que sejam ativas e prazerosas.

\section{CONSIDERAÇÕES FINAIS}

Programas de cursos presenciais para professores, voltados para a melhor utilização dos recursos didáticos disponíveis, que sejam também concebidos tendo como base os princípios de uma proposta articuladora e interacionista, devem ser considerados numa formação continuada de professores, além de cursos à distância, com web cursos, web conferências e web atendimentos que propiciem de fato o estudo e a reflexão constante acerca daquilo que se propõe a fazer de melhor, como ações desenvolvidas pelo conjunto de professores.

O Programa GESTAR, projetos extensionistas itinerantes como Matemática é Show, especializações Arte - Matemática - Língua Portuguesa/IAT-SEC. BA, dentre outros, se constituem em registros de tais possibilidades de capacitações profissionais permanentes.

Podem ocorrer também, com o aporte das distintas modalidades e recursos - jogos educativos, brincadeiras, danças, artes, construção de histórias e atividades lúdicas em geral, para que os professores num processo formativo permanente possam incorporar mais habilidades necessárias para o seu exercício profissional e, consequentemente, encontrar sentido para o que se "ensina" e se "aprende" devidamente associado com a vida em geral.

Desse modo, a percepção atual que se tem sobre Matemática e Arte não deverão contemplar nem um ensino dirigido e baseado em modelos prontos, nem a liberdade completa, sem nenhuma ação do mediador. Trabalha-se com uma visão de linguagem, de comunicação, formada por elementos próprios, que estruturam uma forma de expressão.

Nas atividades ora relatadas, além dos conteúdos específicos que nos propusemos realizar, outras questões do processo educacional foram enfocadas e somadas ao prazer da criação, como as relações afetivas e sociais do grupo, que emergiu durante todo o processo, criando momentos ideais para o grupo se perceber integrado.

Teve-se também, a oportunidade, na formulação do projeto e no andamento das ações, de dialogar com autores que elegeram a Arte, a Matemática e a criatividade como objeto de trabalho, o que nos fez enriquecer significativamente as noções que se tinha inicialmente sobre o assunto.

O processo de conhecimento dos envolvidos esteve diretamente relacionado com a ampliação e reformulação do conhecimento do educador. Os resultados obtidos em face das 
atividades desenvolvidas se mostraram muito estimuladores e ricos, pois é possível a cada dia se revisitar conceitos, conteúdos e práticas pedagógicas, a luz das necessidades da Educação Básica e da formação dos estudantes, os licenciando em Matemática da Universidade. Aprendemos muito e temos muito a aprender.

Cidadania em Ação: Revista de Extensão e Cultura, Florianópolis (SC), v. 2, n.2, juL./dez. 2018. 


\section{REFERÊNCIAS}

BRASIL. Ministério da Educação. Secretaria da Educação Fundamental. Parâmetros Curriculares Nacionais: Matemática. Brasília: MEC; SEM, 1997.

CIFUENTES, J. C. Uma via estética de acesso ao conhecimento matemático. Boletim GEPEM, Rio de Janeiro, n.46, p.55-72, 2005.

CONTADOR, P. R. M. A Matemática na arte e na vida. 2. ed. rev. São Paulo: Livraria da Física, 2011.

D’AMBRÓSIO, U. Educação Matemática: da teoria à prática. 13. ed. Campinas, SP: Papirus, 2006.

DONDIS, D A. Sintaxe da linguagem visual. São Paulo: Martins Fontes, 1997.

FAINGUELERNT, E. K.; NUNES, K. R. A. Fazendo arte com a matemática. Porto Alegre: Artmed, 2006.

FANIZZI, S. A importância da interação nas aulas de Matemática: da elaboração oral à construção de conhecimentos. Revistas Eletrônicas da PUC-SP. Educ. Matem. Pesq., São Paulo, v.14, n.2, p.317-336, 2012. Disponível em: <https://revistas.pucsp.br/index.php/emp /article/viewFile/9443/8156> Acesso em 17 de abril de 2018.

GUSMÃO, L. D. Educação matemática pela arte: uma defesa da educação da sensibilidade no campo da matemática. 2013. 152f. Dissertação (Mestrado em Educação em Ciências e em Matemática). Universidade Federal do Paraná, Curitiba/PR.

HELBEL, A. P. T. Matemática e Arte: possibilidades para o processo de ensino e aprendizagem da Geometria. Os desafios da escola pública paranaense na perspectiva do professor - Produções didático-pedagógicas - Cadernos PDE, 2013.

JORNAL DA UNICAMP. A matemática e o teatro da vida real. Campinas, 2013.

Disponível em: <www.unicamp.br/unicamp/ju/581/matematica-e-o-teatro-da-vida-real>. Acesso em 21 de abril de 2018.

MATHEMA, P. C. Arte e mediação cultural na aula de geometria. 2013. 9f. XI Encontro Nacional de Educação Matemática. Anais... Curitiba/PR, 2013.

MUNARI, B. Das coisas nascem coisas. São Paulo: Martins Fontes, 1998.

Matemática no Universo da Música. Revista Eixo: A Revista Técnico-Científica do Instituto Federal de Brasília. ISSN eletrônico 2238-5630. Disponível em: <http://revistaeixo.ifb.edu.br/index.php/RevistaEixo/article/view/147> Acesso em: 15 de abril de 2018. 
SEMMER, S. Matemática e Arte. Dia a Dia Educação, 2007. Disponível em:

<www.diaadiaeducacao.pr.gov.br/portals/pde/arquivos/409-4.pdf> Acesso em: 20 de abril de 2018.

SILVEIRA, D. da S.; LKAURINO, D. P.; NOVELLO, T. P. Experiências do ensinar e do aprender matemática ao operar as tecnologias digitais na educação superior. REVEMAT Revista Eletrônica de Educação Matemática. Disponível em:

<https://periodicos.ufsc.br/index.php/revemat/article/view/1981-1322.2017v12n2p67> Acesso em 14 de março de 2018.

UNIVERSIDADE FEDERAL DO ESPÍRITO SANTO. Matemática e Dança. Disponível em: <portais4.ufes.br/.../nometese_165_GEAN\%20PIERRE\%20DA\%20SILVA\%20CAMP> Acesso em: 20 de março de 2018

ZALESKI FILHO, Dirceu. Matemática e Arte. Belo Horizonte: Autêntica Editora, 2013.

Cidadania em Ação: Revista de Extensão e Cultura, Florianópolis (SC), v. 2, n.2, juL./dez. 2018. 